(C) 2021, The Authors. Published by Elsevier Inc. and Fass Inc. on behalf of the American Dairy Science Association ${ }^{\circledR}$. This is an open access article under the CC BY-NC-ND license (http://creativecommons.org/licenses/by-nc-nd/4.0/).

\title{
Genomic analyses and biological validation of candidate genes for rectal temperature as an indicator of heat stress in Holstein cattle
}

\author{
Hanpeng Luo, ${ }^{1} \odot$ Xiang Li, ${ }^{1}$ Lirong Hu, ${ }^{1}$ Wei Xu, ${ }^{1}$ Qin Chu, ${ }^{2}$ Aoxing Liu,,${ }^{1,3} \oplus$ Gang Guo, ${ }^{4} \odot$ Lin Liu, ${ }^{5}$ \\ Luiz F. Brito, ${ }^{6}$ () and Yachun Wang ${ }^{1 *}$ () \\ ${ }^{1}$ Key Laboratory of Animal Genetics, Breeding and Reproduction, Ministry of Agriculture of China, National Engineering Laboratory \\ for Animal Breeding, College of Animal Science and Technology, China Agricultural University, 100193, Beijing, China \\ ${ }^{2}$ Institute of Animal Husbandry and Veterinary Medicine, Beijing Academy of Agriculture and Forestry Sciences, 100097, Beijing, China \\ ${ }^{3}$ Center for Quantitative Genetics and Genomics, Department of Molecular Biology and Genetics, Aarhus University, 8830, Tjele, Denmark \\ ${ }^{4}$ Beijing Sunlon Livestock Development Company Limited, 100029, Beijing, China \\ ${ }^{5}$ Beijing Dairy Cattle Center, 100192, Beijing, China \\ ${ }^{6}$ Department of Animal Sciences, Purdue University, West Lafayette, IN 47907
}

\section{ABSTRACT}

Heat stress is a major cause of welfare issues and economic losses to the worldwide dairy cattle industry. Genetic selection for heat tolerance has a great potential to positively affect the dairy industry, as the gains are permanent and cumulative over generations. Rectal temperature (RT) is hypothesized to be a good indicator trait of heat tolerance. Therefore, this study investigated the genetic architecture of RT by estimating genetic parameters, performing genome-wide association studies, and biologically validating potential candidate genes identified to be related to RT in Holstein cattle. A total of 33,013 RT records from 7,598 cows were used in this study. In addition, 1,114 cows were genotyped using the Illumina 150K Bovine BeadChip (Illumina, San Diego, CA). Rectal temperature measurements taken in the morning (AMRT) and in the afternoon (PMRT) are moderately heritable traits, with estimates of $0.09 \pm 0.02$ and $0.04 \pm 0.01$, respectively. These 2 traits are also highly genetically correlated $(\mathrm{r}=0.90$ \pm 0.08 ). A total of 10 SNPs (located on BTA3, BTA4, BTA8, BTA13, BTA14, and BTA29) were found to be significantly associated with AMRT and PMRT. Subsequently, gene expression analyses were performed to validate the key functional genes identified (SPAG17, FAM107B, TSNARE1, RALYL, and PHRF1). This was done through in vitro exposure of peripheral blood mononuclear cells (PBMC) to different temperatures $\left(37^{\circ} \mathrm{C}, 39^{\circ} \mathrm{C}\right.$, and $\left.42^{\circ} \mathrm{C}\right)$. The relative mRNA expression of 2 genes, FAM107B and PHRF1, significantly changed between the control and heat stressed PBMC.

Received April 16, 2020.

Accepted November 15, 2020.

*Corresponding author: wangyachun@cau.edu.cn
In summary, RT is heritable, and enough genetic variability exists to enable genetic improvement of heat tolerance in Holstein cattle. Important genomic regions were identified and biologically validated; $F A M 10^{7} B$ and PHRF1 are the main candidate genes identified to influence heat stress response in dairy cattle.

Key words: animal resilience, Chinese Holstein cattle, genome-wide association study, gene expression, heat stress

\section{INTRODUCTION}

Heat stress is a major welfare and economic constraint to the worldwide dairy cattle industry, especially as global temperatures trend upward (Das et al., 2016; Polsky and von Keyserlingk, 2017; Brito et al., 2020). For instance, heat stress can affect milk production (Carabaño et al., 2014), fertility (Parker-Gaddis et al., 2017), and health and the immune system (Bernabucci et al., 2010; Bagath et al., 2019). The negative effects of heat stress can be mitigated through many approaches, including feeding strategies and environmental control (West, 1999; Berman, 2008; Li et al., 2019). However, these alternatives are usually not cost-effective and tend to be unfeasible in the long term, especially in extensive or semi-intensive production systems. In this context, genetic and genomic selection have been envisioned as a promising alternative for mitigating the negative effects of heat stress in dairy cattle production.

Genetic selection for heat tolerance in dairy cattle has been investigated based on milk performance using reaction norm models (e.g., Nguyen et al., 2016). The main challenge for implementing genetic selection for improved heat tolerance is the definition of closeto-biology phenotypes that can be routinely measured in commercial farms at a low cost to producers. Body temperature is an important physiological parameter in 
the evaluation of health (Burfeind et al., 2012) and welfare state (Allen et al., 2015) of dairy cows and can be useful for improving heat tolerance in cattle (Fisher et al., 2008; Poikalainen et al., 2012). The coping mechanisms to heat stress challenge and its effects on the metabolism of each animal are the result of multiple factors, including behavioral and physiological changes that the animals undergo to regulate body temperature as well as changes at the cellular level such as damage or interruption of cellular function caused by elevated body temperature (Kendall and Webster, 2009; Burfeind et al., 2012; Hansen, 2020).Therefore, when studying heat stress response, it is important to evaluate its effects in a multidimensional fashion (Hansen, 2020). Rectal temperature (RT) is the most common indicator of body temperature and has been widely used as a physiological indicator of heat stress (Godyń et al., 2019; Brito et al., 2020). Rectal temperature has been reported to have variable heritability in dairy cattle depending on the population, with estimates ranging from 0.11 to 0.17 (Mcmillan and Werf, 2007; Dikmen et al., 2012). Because genetic parameters are population specific, a need exists to re-estimate them in Chinese Holstein cattle and using larger data sets. Furthermore, the identification and validation of genomic regions and candidate genes associated with RT is paramount to a better understanding of the biological mechanisms associated with heat stress response in dairy cattle. Therefore, the main objectives of this study were (1) to estimate variance components and heritability for RT; (2) to perform a GWAS for RT; and (3) to biologically validate the candidate genes identified in the previous step by quantifying gene expression through heat stress challenge of peripheral blood mononuclear cells (PBMC).

\section{MATERIALS AND METHODS}

\section{Ethics Committee Approval}

The data collection process was carried out in strict accordance with the protocol approved by the Animal Welfare Committee of the China Agricultural University (Beijing; protocol number: DK996).

\section{Phenotypic Data Collection}

Rectal temperature records of 7,598 lactating Holstein cows from parities 1 to 10 were collected during the summer period (June to August) from 2013 to 2016 in 9 herds located in the Beijing area (China). All housing facilities were equipped with fans and sprinklers. Rectal temperature was measured using a digital thermometer
Table 1. Summary statistics of rectal and dry bulb temperatures in Holstein cows ${ }^{1}$

\begin{tabular}{lllll}
\hline Variable & Mean & SD & Max & Min \\
\hline AMRT $\left({ }^{\circ} \mathrm{C}\right)$ & 38.8 & 0.49 & 42 & 36 \\
PMRT $\left({ }^{\circ} \mathrm{C}\right)$ & 39.19 & 0.61 & 42 & 36 \\
DBT $\left({ }^{\circ} \mathrm{C}\right)$, a.m. & 27.33 & 2.09 & 32.78 & 21.85 \\
DBT $\left({ }^{\circ} \mathrm{C}\right)$, p.m. & 32.17 & 3.22 & 39.08 & 24.43 \\
THI, a.m. & 77.96 & 4.52 & 88.03 & 70.68 \\
THI, p.m. & 82.85 & 3.77 & 90.2 & 75.87 \\
\hline
\end{tabular}

${ }^{1} \mathrm{AMRT}=$ morning rectal temperature: $\mathrm{PMRT}=$ afternoon rectal temperature; $\mathrm{DBT}=$ dry bulb temperature $\left({ }^{\circ} \mathrm{C}\right)$; $\mathrm{THI}=$ temperaturehumidity index; Max = maximum; Min = minimum.

(MC-347, Omron Dalian Co. Ltd., Dalian, China). Cows were measured twice a day between 0630 and $1100 \mathrm{~h}$ and between 1300 and $1830 \mathrm{~h}$ during 2 consecutive days, defined as the morning RT (AMRT) and the afternoon RT (PMRT), respectively. The exact time of RT measurement was not recorded, but we do recommend collecting this information in future studies, as this additional variable could improve the performance of the statistical models used. A total of 33,013 records were collected, with an average of 4 records per cow. Dry bulb temperature (DBT) was also recorded before and after the RT measurements. Dry bulb temperature was assessed using a digital thermometer placed at a height of 1.5 to $2.0 \mathrm{~m}$ above the floor, and averaged values within herd were used in the analyses. Table 1 shows the summary statistics for RT and DBT.

\section{Genetic Parameters for RT}

Variance and covariance components and EBV for AMRT and PMRT were estimated using a bivariate animal model. Pedigrees spanning up to 4 generations were provided by the Dairy Cattle Association of China (Beijing, China) and included 20,545 females and 2,194 males born from 1934 to 2014. The model used for estimation of variance or covariance components and EBV can be described as follows:

$$
\mathbf{y}=\mathbf{X b}+\mathbf{Z}_{\mathrm{a}} \mathbf{a}+\mathbf{Z}_{\mathrm{pe}} \mathbf{p e}+\mathbf{e},
$$

where $\mathbf{y}$ is a vector of phenotypic records (AMRT or PMRT); $\mathbf{b}$ is a vector of fixed effects including herd by testing year (27 levels), parity (3 levels: 1, 2, and $3-10)$, stage of lactation (7 categories based on DIM: 1-50, 51-100, 101-150, 151-200, 201-250, 251-300, or $>300$ ), measurement time (3 levels: before milking, after milking, and unknown), and DBT (as a continuous covariable in the model fitting a linear regression); $\mathbf{X}$ is a design matrix that associates $\mathbf{b}$ with $\mathbf{y}$; $\mathbf{a}$ is the vector of additive genetic effects; pe is the vector of 
random permanent environmental effects; $\mathbf{e}$ is the vector of random residual effects; and $\mathbf{Z}_{\mathrm{a}}$ and $\mathbf{Z}_{\mathrm{pe}}$ are the corresponding incidence matrices. The model assumptions are as follows:

$$
\begin{gathered}
\boldsymbol{a} \sim N\left(0, \mathbf{A} \otimes\left[\begin{array}{cc}
\sigma_{a(A M R T)}^{2} & \sigma_{a(A M R T, P M R T)} \\
\sigma_{a(A M R T, P M R T)} & \sigma_{a(P M R T)}^{2}
\end{array}\right]\right), \\
\boldsymbol{p e} \sim N\left(0, \mathbf{I} \otimes\left[\begin{array}{cc}
\sigma_{p e(A M R T)}^{2} & \sigma_{p e(A M R T, P M R T)} \\
\sigma_{p e(A M R T, P M R T)} & \sigma_{p e(P M R T)}^{2}
\end{array}\right]\right),
\end{gathered}
$$

and

$$
\boldsymbol{e} \sim N\left(0, \mathbf{I} \otimes\left[\begin{array}{cc}
\sigma_{e(A M R T)}^{2} & \sigma_{e(A M R T, P M R T)} \\
\sigma_{e(A M R T, P M R T)} & \sigma_{e(P M R T)}^{2}
\end{array}\right]\right),
$$

where $\sigma_{k(i, j)}^{2}$ is the variance of the effect $\mathbf{k}(\mathbf{k}=\mathbf{a}, \mathbf{p e}$, e) of trait $i, \sigma_{k(i, j)}$ is the covariance between traits $i$ and $j$ for the effect $k, \mathbf{A}$ is the pedigree-based relationship matrix, and $\mathbf{I}$ is an identity matrix. The average information restricted maximum likelihood method was used to estimate (co)variance components using the DMU package (Madsen et al., 2014).

Alternative data sets (or scenarios) were used to estimate variance components and to compare the heritability and standard error (SE) estimates for RT. These data sets were created as (1) only RT records measured when the average DBT was higher than the upper critical temperature $\left(25^{\circ} \mathrm{C}\right.$; Berman et al., 1985; Roenfeldt, 1998); (2) RT records measured in both a.m. and p.m. periods were considered as a single trait (with repeated records), and measurement time (a.m. or p.m.) was included in the statistical model as a fixed effect; (3) the average RT from both a.m. and p.m. measured in the same day was considered as the response variable. The average DBT from a.m. and p.m. in the measurement day was included in the model as covariable. Only cows with AMRT and PMRT measurements in the same day were kept in the data set; and (4) the differences between PMRT and AMRT values in the same day were considered as response variable, and DBT in the afternoon was included as a covariable in the statistical model. Records from 6,213, 7,598, 6,460, and 6,460 cows were included in the analyses of scenarios 1, 2, 3, and 4 , respectively.

\section{Genome-Wide Association Study}

Of all 7,598 cows with RT data, genotypes from 1,114 cows were available from other studies and used for the analyses described here. These animals were genotyped using the Illumina 150K Bovine BeadChip (Illumina Inc., San Diego, CA), which contains 138,892 SNPs. Imputation of missing SNPs was performed using the BEAGLE software (Browning and Browning, 2009), and all the genotyped animals were included in the reference population. Genotype quality control removed SNPs with minor allele frequency $<0.05$, extreme deviation from Hardy-Weinberg equilibrium $(P$-value $<$ $\left.10^{-6}\right)$, and unknown chromosome or genome position. Ultimately, 116,579 SNPs and 1,114 animals were kept for further analyses. The EBV of AMRT and PMRT were used as dependent variable in the GWAS analysis (Supplemental Figure S1, https://doi.org/10.6084/m9 .figshare.13670773). The fixed and random model circuitous probability unification approach (FarmCPU; Liu et al., 2016) was used to perform a single-SNP regression analysis. FarmCPU uses the fixed effect model and the random effect model iteratively. Subsequently, a genome-wide Bonferroni correction threshold of $0.05 / 116,579$ (i.e., $4.29 \times 10^{-7}$ ) was implemented to correct for multiple testing and assess the SNP significance level. Quantile-quantile and Manhattan plots were also created using the "qqman" R package (S. D. Turner, unpublished data: "qqman: An R package for visualizing GWAS results using Q-Q and Manhattan plots").

\section{Functional Analyses}

Positional genes were identified by considering a genomic window of $200 \mathrm{~kb}$ on each side of the significant SNPs (identified in the GWAS analysis described previously). This genomic window was defined based on the level of linkage disequilibrium observed in the population used for this study and supported by the literature (e.g., Sanchez et al., 2017; Mota et al., 2020). The identification of positional genes was performed based on the National Center for Biotechnology Information database (www.ncbi.nlm.nih.gov/gene/) and on the Human Gene Database (www.genecards.org/).

After identifying key candidate genes, we performed a validation analysis in a cell model. Blood samples (20 $\mathrm{mL}$ per cow) were collected from 4 randomly selected healthy cows. The PBMC were isolated by density gradient centrifugation. In brief, blood was diluted, layered over Ficoll, and centrifuged. The mononuclear cell band was recovered and washed twice in PBS. The PBMC 
were resuspended at $2.5 \times 10^{5}$ viable cells per well in 12 -well plates supplemented with $10 \%$ fetal bovine serum medium, $1 \%$ penicillin, and $1 \%$ streptomycin, and maintained at $37^{\circ} \mathrm{C}$ humidified atmosphere with $5 \% \mathrm{CO}_{2}$. The total time between blood collection and culture establishment was less than $6 \mathrm{~h}$. The PBMC were divided into 3 groups (6 repetitions in each group) as follows: control group (CG), heat stress (HS) group one (HS1), and HS group 2 (HS2). First, all of the group samples were incubated at $37^{\circ} \mathrm{C}$ for $24 \mathrm{~h}$. Subsequently, cells were exposed to $37^{\circ} \mathrm{C}(\mathrm{CG}), 39^{\circ} \mathrm{C}$ (HS1), or $42^{\circ} \mathrm{C}$ (HS2) continuously for $1 \mathrm{~h}$.

The level of candidate genes' mRNA was measured by real-time reverse transcription PCR. Total RNA was isolated from PBMC using the Trizol method according to the manufacturer's instructions. cDNA was synthesized using the PrimeScript RT reagent kit (Takara, Dalian, China). qPCR was performed using the SYBR Green I Master kit (Roche Diagnostics GmbH, Mannheim, Germany) on the LightCycler 480 II (Roche Diagnostics) according to the manufacturer's instructions. Bovine $A C T B$ was used as the reference gene to normalize to the geometric mean of the data from target genes using the online tool Primer-BLAST (www.ncbi.nlm .nih.gov/tools/primer-blast/). The primer sequences used for qPCR are shown in Supplemental Table S1 (https://doi.org/10.6084/m9.figshare.13670797). Each RNA sample was analyzed in triplicate. The relative mRNA levels of the candidate genes were determined by the $2^{-\Delta \Delta \mathrm{CT}}$ method (Livak and Schmittgen, 2001). A Duncan test was used to assess the significance of differential gene expression at $P<0.05$.

\section{RESULTS AND DISCUSSION}

\section{Genetic Parameters for RT}

Summary statistics for RT and DBT are shown in Table 1, and the distribution of AMRT and PMRT are presented in Figure 1. Considering that RT is associated with circadian rhythm of metabolic changes when dairy cows are under heat stress during the summer (Shehab-El-Deen et al., 2010), we measured RT in 2 time periods (i.e., 2 traits). The phenotypic standard deviation of PMRT was $0.61^{\circ} \mathrm{C}$ higher than that of AMRT $\left(0.49^{\circ} \mathrm{C}\right)$, which evidenced more phenotypic variance among individuals in the afternoon than in the morning. Despite the small numerical difference, $\mathrm{RT}$ and DBT in the morning were significantly lower compared with the afternoon measurements (paired $t$ test; $P<0.05)$. A similar trend was also observed in a previous study (Lefcourt et al., 1999). Shehab-El-Deen et al. (2010) reported that the standard error of means for RT was higher at 1100, 1500, and $1900 \mathrm{~h}$ compared

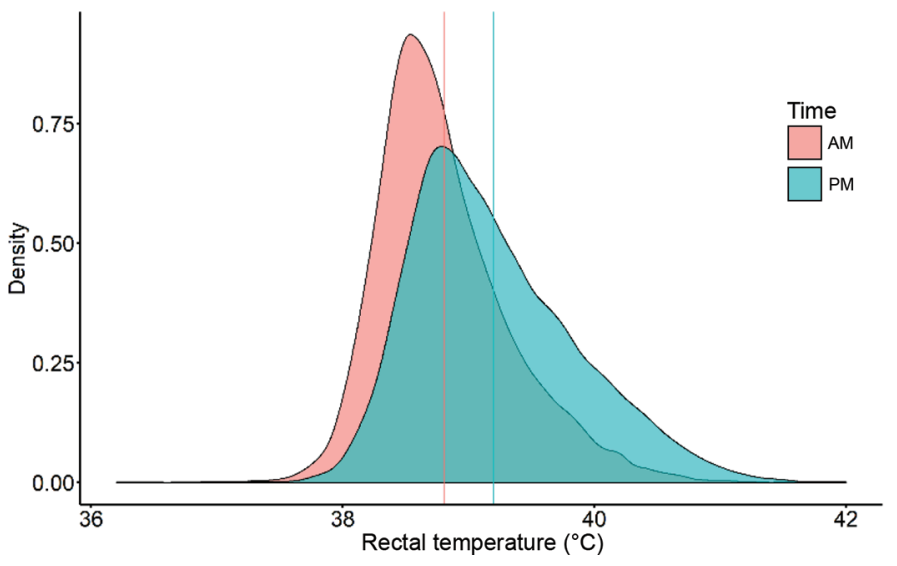

Figure 1. Distribution of rectal temperature in the morning and in the afternoon: average of morning rectal temperature (red line) and afternoon rectal temperature (blue line).

with 2300, 0300, and $0700 \mathrm{~h}$. This indicates that with an increase of DBT, larger variations in RT are usually observed. Body temperature is the result of the balance between heat production and heat loss, and the effect of heat production is more pronounced in highertemperature environments (Atrian and Shahryar, 2012). Thus, our results also indicate that RT in the afternoon (thermal environment with higher temperature) was more influenced by ambient environment. In each time period (AMRT and PMRT), animals were measured at a considerably large interval, and the time of measurement was not recorded. Because a variation in RT likely occurs as DBT increases, including this variable in the statistical models, could improve the results obtained.

The temperature-humidity index (THI) is usually used as the environmental gradient in heat stress studies. However, humidity was not measured during the whole experimental period in this study, and, therefore, DBT was used as the environmental gradient in this study. However, a very high correlation (0.994; $P<0.01)$ was observed between daily DBT and THI (temperature and relative humidity collected by an automatic recorder installed in a Beijing dairy farm from 2018 to 2019), as shown in Supplemental Figure S2 (https://doi.org/10.6084/m9.figshare.13670776). The relationship between DBT and RT is presented in Supplemental Figure S3 (https://doi.org/10.6084/m9 .figshare.13670779), indicating a linear trend, but with large variability at the phenotypic level (consecutive points with common abscissa may be records collected in a herd at the same time). The phenotypic correlations (Pearson correlation) between RT and DBT were 0.25 (a.m.), 0.18 (p.m.), and 0.35 (full data), respectively. We found a downward trend of RT with higher DBT, 
Table 2. Genetic parameters of rectal temperature in lactating Holstein cows based on alternative data sets (or scenarios) ${ }^{1}$

\begin{tabular}{|c|c|c|c|c|c|c|}
\hline Data set & Trait & $\sigma_{a}^{2}$ & $\sigma_{p e}^{2}$ & $\sigma_{e}^{2}$ & Heritability (SE) & Repeatability \\
\hline \multirow[t]{2}{*}{ Full data } & AMRT & 0.018 & 0.035 & 0.160 & $0.09(0.02)$ & 0.25 \\
\hline & PMRT & 0.011 & 0.059 & 0.201 & $0.04(0.01)$ & 0.26 \\
\hline Data with $\mathrm{DBT}>25^{\circ} \mathrm{C}$ & PMRT & 0.013 & 0.059 & 0.210 & $0.05(0.01)$ & 0.26 \\
\hline Full data & $\mathrm{RT}$ & 0.017 & 0.051 & 0.199 & $0.06(0.01)$ & 0.25 \\
\hline Average RT & RT & 0.012 & 0.063 & 0.247 & $0.04(0.04)$ & 0.23 \\
\hline Difference of RT & RT & 0.002 & 0.022 & 0.281 & $0.01(0.01)$ & 0.08 \\
\hline
\end{tabular}

${ }^{1} \mathrm{DBT}=$ dry bulb temperature $\left({ }^{\circ} \mathrm{C}\right) ; \mathrm{RT}=$ rectal temperature; AMRT $=$ morning rectal temperature; PMRT $=$ afternoon rectal temperature; $\sigma_{a}^{2}, \sigma_{p e}^{2}$, and $\sigma_{e}^{2}=$ estimated additive, permanent, and residual variances, respectively; $\mathrm{SE}=$ standard error of estimates; data with $\mathrm{DBT}>25^{\circ} \mathrm{C}$ $=$ measurements when DBT was higher than $25^{\circ} \mathrm{C}$; average $\mathrm{RT}=$ average of AMRT and PMRT within the same day; difference of RT $=$ deviation of AMRT to PMRT within the same day.

which might be associated with the reduced number of records under extreme DBT. During DBT exceeding $30^{\circ} \mathrm{C}$ in the morning, a downward trend of RT also occurs. However, average RT is still increasing under the DBT of $30^{\circ} \mathrm{C}$ to $35^{\circ} \mathrm{C}$, when more data were available in the DBT range for p.m. and full data (including a.m. and p.m.).

Table 2 presents the heritability estimates obtained in each scenario and trait. In general, the heritability estimates were in the lower range, but we found significant genetic variability, indicating that genetic progress can be achieved through direct selection for RT. Little improvement in the heritability estimates was detectable when analyzing RT in different ways, such as including only records associated with DBT higher than the upper critical temperature $\left(25^{\circ} \mathrm{C}\right)$ or considering AMRT and PMRT as a single trait in a repeatability model (Table 2 ). Therefore, we have focused on the discussion of the results when considering the full data set and treating AMRT and PMRT as 2 traits. The heritability estimates of AMRT and PMRT were low but significant: $0.09 \pm 0.02$ and $0.04 \pm 0.01$ for AMRT and PMRT, respectively (Table 2). The repeatability of PMRT (0.26) is similar to that of AMRT (0.25). Additionally, both traits were highly genetically correlated $(\mathrm{r}=0.90 \pm 0.08)$, indicating that AMRT is a better indicator of RT, as it has the highest heritability estimate. In a US Holstein population, Dikmen et al. (2012) reported a heritability of $0.17 \pm 0.13$ for PMRT (measured between 1300 and $1830 \mathrm{~h}$ ) during the summer, which is slightly higher than the estimate observed in the current study. However, the SE of their estimate was larger and might be due to the difference in sample size $(7,598$ vs. 1,695$)$. The heritability of AMRT was higher than PMRT, indicating a greater environmental effect in the afternoon measurements. Similar DBT were observed during the whole afternoon period (1300-1830 h; Supplemental Table S2, https://doi.org/10.6084/m9 .figshare.13670815), but the times of measurement were not recorded in this study, which could have negatively influenced the estimation of genetic parameters in this study. A decrease of the heat load during the night usually leads to a body temperature reduction in the morning and a circadian rhythm of the body temperature (body temperature in the afternoon is usually higher than in the morning), as observed in the present study and reported in the literature (Piccione et al., 2003; Shehab-El-Deen et al., 2010). This difference in the phenotypic mean and variance for AMRT and PMRT may result in the heritability differences obtained for AMRT and PMRT. Thus, as previously mentioned, the exact time of measurement should be recorded and included in further analyses, as it likely influenced the heritability estimates reported in this study. The higher estimated heritability under lower DBT (in the morning) observed in this study are similar to those reported for RT in crossbred animals (Brahman $\times$ Angus; SarloDavila et al., 2019).

The heritability of body temperature under low THI conditions $\left(\mathrm{h}^{2}=0.32 \pm 0.18\right)$ has been reported to be slightly higher than that of body temperature under high $\left(h^{2}=0.26 \pm 0.16\right)$ THI conditions (Sarlo-Davila et al., 2019), which is consistent with our results showing that heritability for AMRT were higher than for PMRT. The higher estimates in heritability reported by SarloDavila et al. (2019) compared with the present study might be due to the use of RT (this study) rather than vaginal temperature (potentially different traits) and measurements in dairy cows (this study) rather than beef cattle (Howard et al., 2014), which is an important factor considering that genetic parameters are population specific. Furthermore, the permanent environmental variance and repeatability of PMRT is similar to that of AMRT. The permanent environmental variance represents the variance of permanent or nonlocalized differences between individuals, and repeatability is the correlation between the repeated measurements of the same individual.

In summary, RT is a polygenic trait, and despite the low heritability estimates observed for AMRT and 

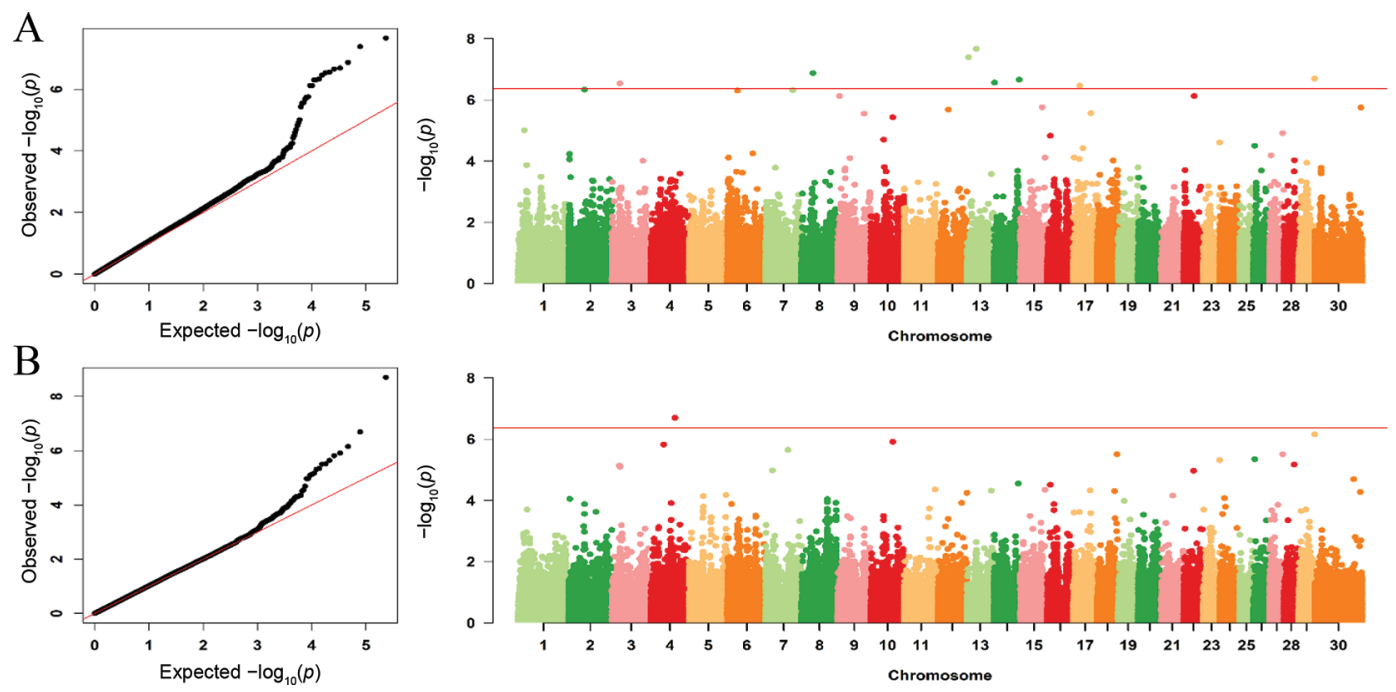

Figure 2. Results of the genome-wide association studies for morning rectal temperature (A) and afternoon rectal temperature (B). The negative logarithm of the observed (y-axis) and the expected (x-axis) $P$-values are plotted for each SNP in the Manhattan plots in the right-hand panels. The deviations of the signals from the null hypothesis are illustrated as the quantile-quantile plots in the left-hand panels.

PMRT, genetic progress for heat tolerance can still be achieved through direct genetic or genomic selection. Furthermore, we expect that an effective selection scheme to improve heat tolerance should be based on multiple indicators (combined through a selection index), including additional physiological indicators as well as reaction norms based on production and reproduction traits. For instance, the slope of a regression for productive or reproductive performance on environmental gradient (e.g., environmental temperature, THI) as covariates can be used to select more heat-tolerant individuals (Ravagnolo and Misztal, 2000; Carabaño et al., 2014; Nguyen et al., 2016; Mota et al., 2020). Our group is also investigating additional physiological indicators of heat stress response in dairy cattle. A comprehensive selection subindex containing physiological, productive, and reproductive indicators is likely to be the optimal alternative to implement genetic or genomic selection, or both, for improved heat tolerance in dairy cattle.

\section{Genome-Wide Association Study}

The Manhattan and quantile-quantile plots for the GWAS results of AMRT and PMRT are shown in Figure 2. Ten genome-wide significant SNPs (Table 3) located on BTA3, BTA4, BTA8, BTA13, BTA14, BTA17, and BTA29, respectively, were identified for AMRT and PMRT, respectively $\left(P<4.29 \times 10^{-7}\right)$. The minor allele frequency of significant SNPs ranged from 0.17 (ARS-BFGL-BAC-26939) to 0.46 (BovineHD1700005860), and the $P$-values ranged from $2.18 \times$ $10^{-8}$ (ARS-BFGL-NGS-86864) to $3.47 \times 10^{-7}$ (Bovine-
HD1700005860). One SNP (BovineHD1300001265) was found to be significantly associated with both AMRT and PMRT. The quantile-quantile plots indicate that potential population stratification seems to have been properly accounted for in the GWAS analyses. It was expected that a larger number of significant SNPs would be identified. However, the results observed might be due to the highly polygenic nature of heat tolerance, in which each variant has a small effect (and is thus difficult to identify) in the phenotype measured, and the low heritability of the traits evaluated. Additional studies using whole-genome sequence data, larger data sets, and more comprehensive statistical models (e.g., reaction norm model and random regression model; Oliveira et al., 2019) will be carried out in the near future.

By searching for flanking regions $\pm 200 \mathrm{~kb}$ nearby significant SNPs, 5 candidate genes SPAG17, FAM107B, TSNARE1, RALYL, and PHRF1 covering or nearby 6 SNPs were detected in BTA3, BTA13, BTA14, and BTA29 associated with AMRT. However, no genes were found near the 2 SNPs in BTA4 and BTA 8 associated with PMRT. To date, few studies have reported GWAS for RT in dairy cattle. Dikmen et al. (2013) identified several genomic regions located in BTA5, BTA16, and BTA24 associated with PMRT. Sigdel et al. (2019) performed whole-genome scans and a subsequent gene-set analysis for identifying candidate genes and functional gene-sets implicated in milk production under heat stress conditions, and identified 3 different genomic regions on BTA5, BTA14, and BTA15. Among the 5 genes detected in the current study, SPAG17 en- 


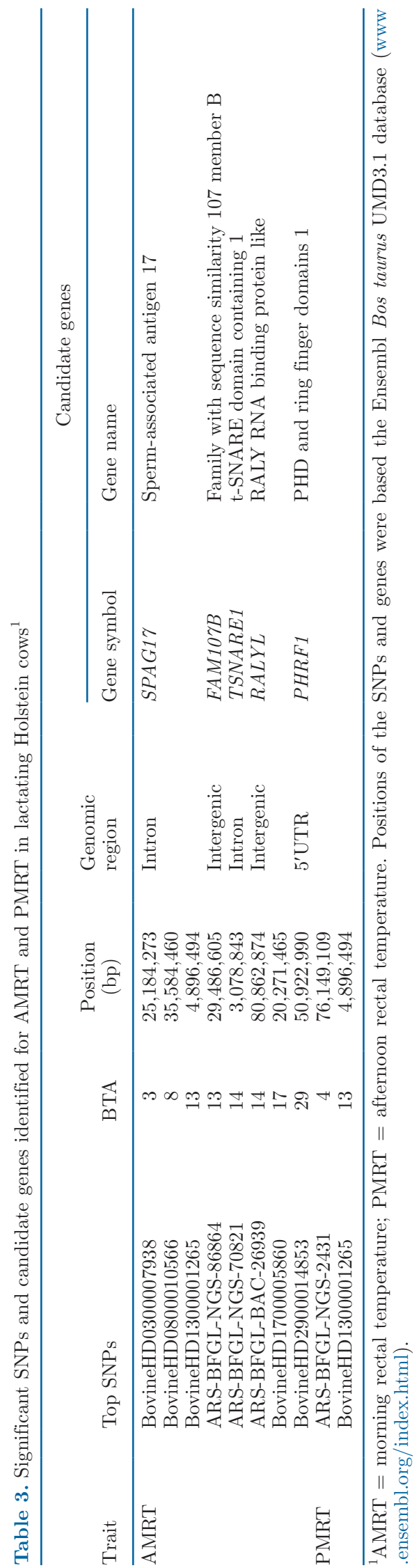

codes a central pair protein present in the axonemes of cells that was previously reported to be associated with growth rate in mice (Teves et al., 2015) and pigs (Fontanesi et al., 2014). The TSNARE1 gene may have a vertebrate-specific role in intracellular protein transport and synaptic vesicle exocytosis, and a recent study suggested its development within the vertebrate lineage from the harbinger transposon super family (Smith et al., 2012) and was proposed to be a candidate gene of milk yield, fat yield, and protein yield (Jiang et al., 2019). The gene $R A L Y L$ is related to nucleic acid binding and identical protein binding. An important paralog of this gene $R A L Y L$ is $R A L Y$, which encodes a member of the heterogeneous nuclear ribonucleoprotein gene family and is responsible for pre-mRNA splicing and has a role in embryonic development (Khrebtukova et al., 1999). Moreover, RALYL was identified in the genomic region related to resistance to bovine viral diarrhea virus (Casas et al., 2015). Two genes, PHRF1, containing the significant SNP BovineHD2900014853 on BTA29, and FAM107B, near the significant SNP ARS-BFGL-NGS-86864 on BTA13, were most likely to be the main candidate genes based on differentially gene expression after different temperature treatment and biological function screening. The PHRF1 gene could promote the genome integrity by modulating nonhomologous end-joining upon DNA damage insults (Chang et al., 2015), so it may help repair cell damage caused by heat shock. The FAM107B gene is a member of the gene family with sequence similarity 107 . The FAM107 members contain an N-terminal domain, which is conserved across species (e.g., human, rat, and drosophila) and regarded as heat shock-inducible tumor small protein that carried the promoter region providing heat shock transcription factor (Nakajima et al., 2010). FAM107B was expressed during embryogenesis and in adulthood, with a particularly high and specific expression in the form of telencephalon depicting an involvement in corticogenesis, which is one of the main stress hormones (Masana et al., 2015).

Other GWAS have been performed based on other indicators of heat stress response. For instance, Otto et al. (2019) performed GWAS and post-GWAS analyses for the variation between 2 consecutive RT measurements in a crossbreed population (Gir $\times$ Holstein). Genes involved with biological processes in response to heat stress effects (LIF, OSM, TXNRD2, and DGCR8) were identified as putative candidate genes. Moreover, principal component analyses for milk yield, fat and protein percentages, and somatic cell score were used to develop measures of tolerance to heat stress in Italian Holstein population, and 8 SNPs were detected relating to heat tolerance. The overlap of QTL associated with thermotolerance or heat stress is low, so we need 
expand the population and explore more traits related to heat stress to research the mechanisms of heat stress.

\section{Candidate Gene Expression}

In addition to performing GWAS, we also aimed to validate the relationship between candidate genes identified in the GWAS and RT using a PBMC model, a cell commonly used in testing the response of heat shock proteins (Lacetera et al., 2006; Bhanuprakash et al., 2016). The mRNA levels of the 5 candidate genes are shown in Figure 3. A significant increase in FAM107B mRNA was observed in PMBC exposed to $39^{\circ} \mathrm{C}$ and $42^{\circ} \mathrm{C}$ compared with $\mathrm{CG}\left(37^{\circ} \mathrm{C}\right)$. When the temperature was raised to $42^{\circ} \mathrm{C}$, the expression of PHRF1 mRNA was significantly higher than CG. The other candidate
SPAG17

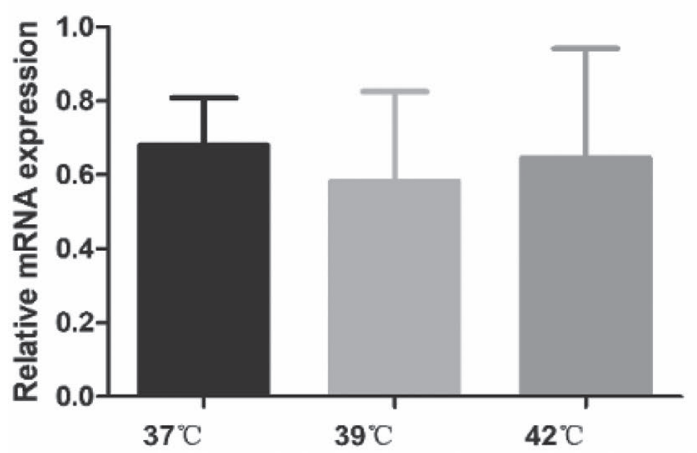

TSNARE1

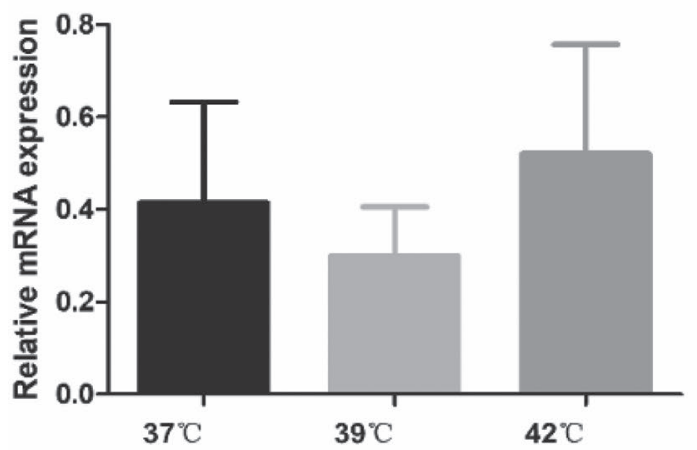

PHRF1

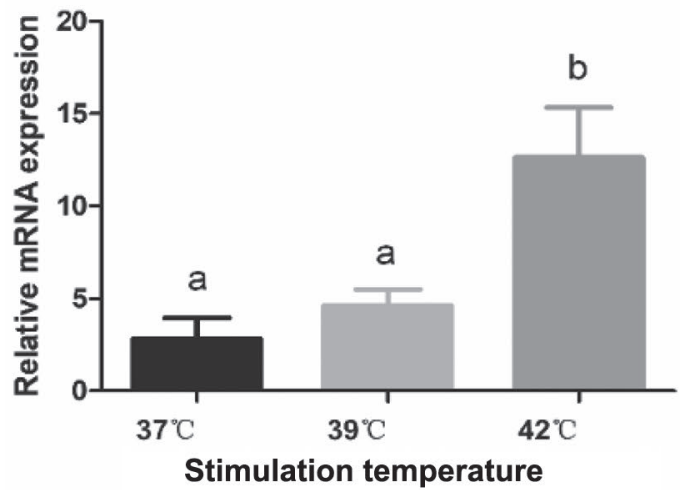

FAM107B

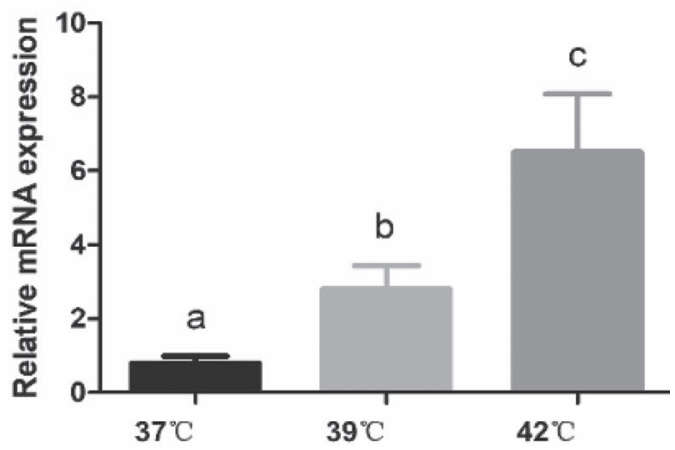

RALYL

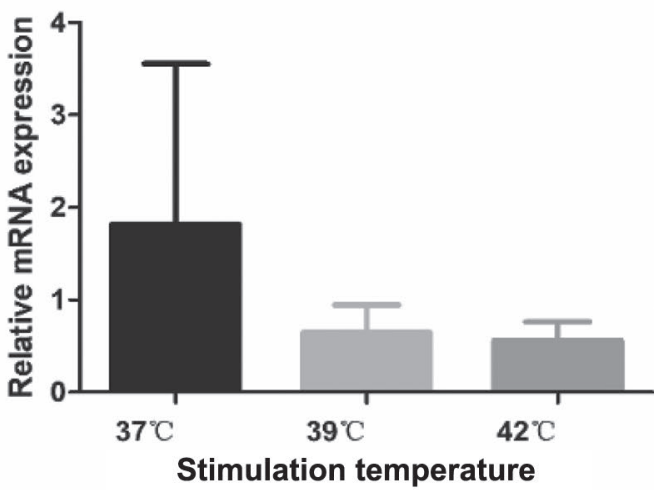

Figure 3. Levels of mRNA (expressed in arbitrary units relative to expression of $A C T B$ mRNA) for treatments of different temperature. Values with different lowercase letters indicate a statistically significant difference $(P<0.05)$. Error bars indicate SD. 
genes (SPAG17, TSNARE1, and RALYL) did not have significant responses for short-term exposure to heat shock conditions. Increase of PHRF1 and FAM107B expression in PBMC might function as a biological indicator for changes in the stress level. These observations may imply that FAM107B and PHRF1 are important candidate genes for RT. Despite the importance of validation in cell models, we acknowledge that the responses in the individuals themselves (dairy cows) might be different. This is because each cell type might respond in a different way when exposed to heat stress challenge. Therefore, future studies should also perform in vivo validation of these candidate genes identified. Khan et al. (2020) evaluated the physiological and molecular response of bovine granulosa cells to different heat stress intensities in vitro. The genes FAM107B and PHRF1 were significantly and differentially expressed in the treatments (control: $38^{\circ} \mathrm{C}$ and case: $39^{\circ} \mathrm{C}, 40^{\circ} \mathrm{C}$, and $41^{\circ} \mathrm{C}$ ). After $42^{\circ} \mathrm{C}$ stimulating rats for $120 \mathrm{~min}$, different expression of those 2 genes were also observed $(P<0.05)$ in adrenal glands (Dou et al., 2020).

\section{Implications and Future Studies}

First, it is important to evaluate additional physiological indicators of heat stress, which is an area that our group is currently working on. In the long term, we expect to develop a selection subindex for heat tolerance based on multiple indicators of heat stress response. Automated data collection and high-throughput phenotypes will also be of great value for selection to improved heat tolerance (as reviewed by Brito et al., 2020). It is also important that the genomic regions identified in this population are validated in other Holstein populations as well as in other dairy cattle breeds. The SNPs and genomic regions identified in this study can be used to improve the accuracy of genomic prediction for heat tolerance. For instance, the key SNPs identified can be included in low-density SNP panels to increase accuracy of genomic predictions based on imputed genotypes, or one can incorporate biological information (known genomic regions) in the prediction models though Bayesian approaches or weighted singlestep GWAS.

\section{CONCLUSIONS}

Morning and afternoon rectal temperatures are polygenic and heritable traits in Holstein cattle and therefore can be improved through genetic or genomic selection. Both traits are highly correlated at the genetic level, indicating that indirect genetic progress would be obtained through direct selection for only 1 of the 2 traits. Eight significant SNPs located on BTA3,
BTA4, BTA8, BTA13, BTA14, BTA17, and BTA29 were identified to be associated with rectal temperature, harboring 5 candidate genes (SPAG17, FAM107B, TSNARE1, RALYL, and PHRF1). Two candidate genes (FAM10'B and PHRF1) were validated through functional analysis based on a gene expression for temperature challenge in a peripheral blood mononuclear cell model.

\section{ACKNOWLEDGMENTS}

The authors acknowledge the Beijing Dairy Cattle Center and Beijing Sunlon Livestock Development Company Limited for providing access to the datasets used and enabling data collection at their farms. The authors are also grateful to the members of the COWINFO group at the China Agricultural University (Beijing) for helping to measure rectal temperature in a large number of animals, especially Lu Cao, Zezhao Wang, Xinyi Yan, Hetian Huang, Rui Shi, and Ye Wang. We also thank Xu Zhang (Huazhong University of Science and Technology, Wuhan, China), for sharing his expertise about the use of FarmCPU. The authors declare that the research was conducted in the absence of any commercial or financial relationship that could be construed as a potential conflict of interest.

\section{REFERENCES}

Allen, J. D., L. W. Hall, R. J. Collier, and J. F. Smith. 2015. Effect of core body temperature, time of day, and climate conditions on behavioral patterns of lactating dairy cows experiencing mild to moderate heat stress. J. Dairy Sci. 98:118-127. https://doi.org/10 .3168/jds.2013-7704.

Atrian, P., and H. A. Shahryar. 2012. Heat stress in dairy cows: A review. Res. Zool. 2:31-37. https://doi.org/10.5923/j.zoology .20120204.03.

Bagath, M., G. Krishnan, C. Devaraj, V. P. Rashamol, P. Pragna, A. M. Lees, and V. Sejian. 2019. The impact of heat stress on the immune system in dairy cattle: A review. Res. Vet. Sci. 126:94-102. https://doi.org/10.1016/j.rvsc.2019.08.011.

Berman, A. 2008. Increasing heat stress relief produced by coupled coat wetting and forced ventilation. J. Dairy Sci. 91:4571-4578. https://doi.org/10.3168/jds.2008-1175.

Berman, A., Y. Folman, M. Kaim, M. Mamen, Z. Herz, D. Wolfenson, A. Arieli, and Y. Graber. 1985. Upper critical temperatures and forced ventilation effects for high-yielding dairy cows in a subtropical climate. J. Dairy Sci. 68:1488-1495. https://doi.org/10.3168/ jds.S0022-0302(85)80987-5.

Bernabucci, U., N. Lacetera, L. H. Baumgard, R. P. Rhoads, B. Ronchi, and A. Nardone. 2010. Metabolic and hormonal acclimation to heat stress in domesticated ruminants. Animal 4:1167-1183. https: //doi.org/10.1017/S175173111000090X.

Bhanuprakash, V., U. Singh, G. Sengar, B. Sajjanar, B. Bhusan, T. V. Raja, R. Alex, S. Kumar, R. Singh, A. Kumar, R. R. Alyethodi, S. Kumar, and R. Deb. 2016. Differential effect of thermal stress on HSP70 expression, nitric oxide production and cell proliferation among native and crossbred dairy cattle. J. Therm. Biol. 59:18-25. https://doi.org/10.1016/j.jtherbio.2016.04.012.

Brito, L. F., H. R. Oliveira, B. McConn, A. P. Schinckel, A. Arrazola, J. N. Marchant-Forde, and J. Johnson. 2020. Large-scale phenotyping of livestock welfare in commercial production systems: A 
new frontier in animal breeding. Front. Genet. 11:793. https://doi .org/10.3389/fgene.2020.00793.

Browning, B. L., and S. R. Browning. 2009. A unified approach to genotype imputation and haplotype-phase inference for large data sets of trios and unrelated individuals. Am. J. Hum. Genet. 84:210-223. https://doi.org/10.1016/j.ajhg.2009.01.005.

Burfeind, O., V. S. Suthar, and W. Heuwieser. 2012. Effect of heat stress on body temperature in healthy early postpartum dairy cows. Theriogenology 78:2031-2038. https://doi.org/10.1016/j theriogenology.2012.07.024.

Carabaño, M. J., K. Bachagha, M. Ramón, and C. Díaz. 2014. Modeling heat stress effect on Holstein cows under hot and dry conditions: Selection tools. J. Dairy Sci. 97:7889-7904. https://doi.org/ 10.3168/jds.2014-8023.

Casas, E., B. E. Hessman, J. W. Keele, and J. F. Ridpath. 2015. A genome-wide association study for the incidence of persistent bovine viral diarrhea virus infection in cattle. Anim. Genet. 46:8-15. https://doi.org/10.1111/age.12239.

Chang, C.-F., P.-C. Chu, P.-Y. Wu, M.-Y. Yu, J.-Y. Lee, M.-D. Tsai, and M.-S. Chang. 2015. PHRF1 promotes genome integrity by modulating non-homologous end-joining. Cell Death Dis. 6:e1716. https://doi.org/10.1038/cddis.2015.81.

Das, R., L. Sailo, N. Verma, P. Bharti, J. Saikia, Imtiwati, and R. Kumar. 2016. Impact of heat stress on health and performance of dairy animals: A review. Vet. World 9:260-268. https://doi.org/10 .14202 /vetworld.2016.260-268

Dikmen, S., J. B. Cole, D. J. Null, and P. J. Hansen. 2012. Heritability of rectal temperature and genetic correlations with production and reproduction traits in dairy cattle. J. Dairy Sci. 95:3401-3405. https://doi.org/10.3168/jds.2011-4306.

Dikmen, S., J. B. Cole, D. J. Null, and P. J. Hansen. 2013. Genomewide association mapping for identification of quantitative trait loci for rectal temperature during heat stress in Holstein cattle. PLoS One 8:e69202. https://doi.org/10.1371/journal.pone.0069202.

Dou, J., A. Khan, M. Z. Khan, S. Mi, Y. Wang, Y. Yu, and Y. Wang. 2020. Heat stress impairs the physiological responses and regulates genes coding for extracellular exosomal proteins in rat. Genes (Basel) 11:306. https://doi.org/10.3390/genes11030306.

Fisher, A. D., N. Roberts, S. J. Bluett, G. A. Verkerk, and L. R. Matthews. 2008. Effects of shade provision on the behaviour, body temperature and milk production of grazing dairy cows during a New Zealand summer. N. Z. J. Agric. Res. 51:99-105. https://doi .org/10.1080/00288230809510439.

Fontanesi, L., G. Schiavo, G. Galimberti, D. G. Calò, and V. Russo. 2014. A genomewide association study for average daily gain in Italian Large White pigs. J. Anim. Sci. 92:1385-1394. https://doi .org/10.2527/jas.2013-7059.

Godyń, D., P. Herbut, and S. Angrecka. 2019. Measurements of peripheral and deep body temperature in cattle $-\mathrm{A}$ review. J. Therm. Biol. 79:42-49. https://doi.org/10.1016/j.jtherbio.2018.11.011.

Hansen, P. J. 2020. Prospects for gene introgression or gene editing as a strategy for reduction of the impact of heat stress on production and reproduction in cattle. Theriogenology 154:190-202. https:// doi.org/10.1016/j.theriogenology.2020.05.010.

Howard, J. T., S. D. Kachman, W. M. Snelling, E. J. Pollak, D. C. Ciobanu, L. A. Kuehn, and M. L. Spangler. 2014. Beef cattle body temperature during climatic stress: A genome-wide association study. Int. J. Biometeorol. 58:1665-1672. https://doi.org/10.1007/ s00484-013-0773-5.

Jiang, J., L. Ma, D. Prakapenka, P. M. VanRaden, J. B. Cole, and Y. Da. 2019. A large-scale genome-wide association study in U.S. Holstein cattle. Front. Genet. 10:412. https://doi.org/10.3389/fgene 2019.00412 .

Kendall, P. E., and J. R. Webster. 2009. Season and physiological status affects the circadian body temperature rhythm of dairy cows. Livest. Sci. 125:155-160. https://doi.org/10.1016/j.livsci.2009.04 .004 .

Khan, A., J. Dou, Y. Wang, X. Jiang, M. Z. Khan, H. Luo, T. Usman, and H. Zhu. 2020. Evaluation of heat stress effects on cellular and transcriptional adaptation of bovine granulosa cells. J. Anim. Sci. Biotechnol. 11:25. https://doi.org/10.1186/s40104-019-0408-8.
Khrebtukova, I., A. Kuklin, R. P. Woychik, and E. J. Michaud. 1999 Alternative processing of the human and mouse Raly genes. Biochim. Biophys. Acta 1447:107-112. https://doi.org/10.1016/S0167 -4781(99)00126-8.

Lacetera, N., U. Bernabucci, D. Scalia, L. Basiricò, P. Morera, and A. Nardone. 2006. Heat stress elicits different responses in peripheral blood mononuclear cells from Brown Swiss and Holstein Cows. J. Dairy Sci. 89:4606-4612. https://doi.org/10.3168/jds.S0022 $-0302(06) 72510-3$.

Lefcourt, A. M., J. B. Huntington, R. M. Akers, D. L. Wood, and J. Bitman. 1999. Circadian and ultradian rhythms of body temperature and peripheral concentrations of insulin and nitrogen in lactating dairy cows. Domest. Anim. Endocrinol. 16:41-55. https: //doi.org/10.1016/S0739-7240(98)00047-2.

Li, G., Z. Wang, Z. Shi, T. Ding, Q. He, and S. Hong. 2019. Analysing the motions of spray droplets on a cows surface to relieve heat stress. Sci. Rep. 9. https://doi.org/10.1038/s41598-018-38354-0.

Liu, X., M. Huang, B. Fan, E. S. Buckler, and Z. Zhang. 2016. Iterative usage of fixed and random effect models for powerful and efficient genome-wide association studies. PLoS Genet. 12:e1005767. https://doi.org/10.1371/journal.pgen.1005767.

Livak, K. J., and T. D. Schmittgen. 2001. Analysis of relative gene expression data using real-time quantitative PCR and the $2^{-\triangle \Delta C 1}$ method. Methods 25:402-408. https://doi.org/10.1006/meth.2001 1262 .

Madsen, P. M. V., H. D. Ding, F. O. Christensen, and J. Jensen. 2014. DMU - A package for analyzing multivariate mixed models in quantitative genetics and genomics. In Proc. 10th World Congress of Genetics Applied to Livestock Production, Vancouver, Canada.

Masana, M., M. M. Jukic, A. Kretzschmar, K. V. Wagner, S. Westerholz, M. V. Schmidt, T. Rein, C. Brodski, and M. B. Müller. 2015. Deciphering the spatio-temporal expression and stress regulation of Fam107B, the paralog of the resilience-promoting protein DRR1 in the mouse brain. Neuroscience 290:147-158. https://doi.org/10 .1016/j.neuroscience.2015.01.026.

Mcmillan, A. M., and J. H. J. V. Werf. 2007. Genetic variation in rectal temperature and its association with heat tolerance in Australian dairy cattle. Pages 553-556 in Proc. 17th Conference of the Association for the Advancement of Animal Breeding and Genetics, Sep. 23-26, Armidale, New South Wales, Australia.

Mota, L. F. M., F. B. Lopes, G. A. Fernandes Júnior, G. J. M. Rosa, A. F. B. Magalhães, R. Carvalheiro, and L. G. Albuquerque. 2020. Genome-wide scan highlights the role of candidate genes on phenotypic plasticity for age at first calving in Nellore heifers. Sci. Rep. 10:6481. https://doi.org/10.1038/s41598-020-63516-4.

Nakajima, H., Y. Ishigaki, Q. Xia, T. Ikeda, Y. Yoshitake, H. Yonekura, T. Nojima, T. Tanaka, H. Umehara, N. Tomosugi, T. Takata, T. Shimasaki, N. Nakaya, I. Sato, K. Kawakami, K. Koizumi, T. Minamoto, and Y. Motoo. 2010. Induction of HITS, a newly identified family with sequence similarity 107 protein (FAM107B), in cancer cells by heat shock stimulation. Int. J. Oncol. 37:583. https: //doi.org/10.3892/ijo_00000707.

Nguyen, T. T. T., P. J. Bowman, M. Haile-Mariam, J. E. Pryce, and B. J. Hayes. 2016. Genomic selection for tolerance to heat stress in Australian dairy cattle. J. Dairy Sci. 99:2849-2862. https://doi .org/10.3168/jds.2015-9685.

Oliveira, H. R., L. F. Brito, D. A. L. Lourenco, F. F. Silva, J. Jamrozik, L. R. Schaeffer, and F. S. Schenkel. 2019. Invited review: Advances and applications of random regression models: From quantitative genetics to genomics. J. Dairy Sci. 102:7664-7683. https://doi.org/10.3168/jds.2019-16265.

Otto, P. I., S. E. F. Guimaraes, L. L. Verardo, A. L. S. Azevedo, J. Vandenplas, C. A. Sevillano, D. B. D. Marques, M. D. F. A. Pires, C. de Freitas, and R. D. S. Verneque. 2019. Genome-wide association studies for heat stress response in Bos taurus $\times$ Bos indicus crossbred cattle. J. Dairy Sci. 102:8148-8158. https://doi.org/10 $.3168 /$ jds.2018-15305.

Parker Gaddis, K. L., S. Dikmen, D. J. Null, J. B. Cole, and P. J. Hansen. 2017. Evaluation of genetic components in traits related to superovulation, in vitro fertilization, and embryo transfer in 
Holstein cattle. J. Dairy Sci. 100:2877-2891. https://doi.org/10 3168/jds.2016-11907.

Piccione, G., G. Caola, and R. Refinetti. 2003. Daily and estrous rhythmicity of body temperature in domestic cattle. BMC Physiol. 3:7. https://doi.org/10.1186/1472-6793-3-7.

Poikalainen, V., J. Praks, I. Veermäe, and E. Kokin. 2012. Infrared temperature patterns of cow's body as an indicator for health control at precision cattle farming. Agron. Res. (Tartu) 10:187-194.

Polsky, L., and M. A. von Keyserlingk. 2017. Invited review: Effects of heat stress on dairy cattle welfare. J. Dairy Sci. 100:8645-8657. https://doi.org/10.3168/jds.2017-12651.

Ravagnolo, O., and I. Misztal. 2000. Genetic component of heat stress in dairy cattle, parameter estimation. J. Dairy Sci. 83:2126-2130. https://doi.org/10.3168/jds.S0022-0302(00)75095-8.

Roenfeldt, S. 1998. You can't afford to ignore heat stress. Dairy Herd Management. 35:6-12.

Sanchez, M. P., A. Govignongion, P. Croiseau, S. Fritz, C. Hoze, G. Miranda, P. Martin, A. Barbatleterrier, R. Letaief, D. Rocha, M. Brochard, M. Boussaha, and D. Boichard. 2017. Within-breed and multi-breed GWAS on imputed whole-genome sequence variants reveal candidate mutations affecting milk protein composition in dairy cattle. Genet. Sel. Evol. 49:68. https://doi.org/10.1186/ s12711-017-0344-z.

Sarlo Davila, K. M., H. Hamblen, P. J. Hansen, S. Dikmen, P. A. Oltenacu, and R. G. Mateescu. 2019. Genetic parameters for hair characteristics and core body temperature in a multibreed Brahman-Angus herd. J. Anim. Sci. 97:3246-3252. https://doi.org/10 $.1093 / \mathrm{jas} / \mathrm{skz} 188$.

Shehab-El-Deen, M. A. M. M., M. S. Fadel, A. Van Soom, S. Y. Saleh, D. Maes, and J. L. M. R. Leroy. 2010. Circadian rhythm of meta- bolic changes associated with summer heat stress in high-producing dairy cattle. Trop. Anim. Health Prod. 42:1119-1125. https:// doi.org/10.1007/s11250-010-9534-1.

Sigdel, A., R. Abdollahiarpanahi, I. Aguilar, and F. Penagaricano. 2019. Whole genome mapping reveals novel genes and pathways involved in milk production under heat stress in US Holstein cows. Front. Genet. 10:928. https://doi.org/10.3389/fgene.2019.00928.

Smith, J. J., K. Sumiyama, and C. T. Amemiya. 2012. A living fossil in the genome of a living fossil: Harbinger transposons in the coelacanth genome. Mol. Biol. Evol. 29:985-993. https://doi.org/ $10.1093 / \mathrm{molbev} / \mathrm{msr} 267$.

Teves, M. E., G. Sundaresan, D. J. Cohen, S. L. Hyzy, I. Kajan, M. Maczis, Z. Zhang, R. M. Costanzo, J. Zweit, Z. Schwartz, B. D Boyan, and J. F. Strauss. 2015. SPAG17 deficiency results in skeletal malformations and bone abnormalities. PLoS One 10:e0125936. https://doi.org/10.1371/journal.pone.0125936.

West, J. W. 1999. Nutritional strategies for managing the heat-stressed dairy cow. J. Anim. Sci. 77(Suppl. 2):21-35. https://doi.org/10 .2527/1997.77suppl_221x.

\section{ORCIDS}

Hanpeng Luo (ㄴ) https://orcid.org/0000-0001-6211-3834

Aoxing Liu (ํ) https://orcid.org/0000-0002-9155-1494

Gang Guo $\odot$ https://orcid.org/0000-0001-8677-6325

Luiz F. Brito @ https://orcid.org/0000-0002-5819-0922

Yachun Wang @ https://orcid.org/0000-0003-3629-2802 